\title{
Article
}

\section{Beyond opposition and acceptance: examining public perceptions of the environmental and health impacts of unconventional oil and gas extraction}

Cotton, Matthew and Charnley-Parry, Ioan

Available at http://clok.uclan.ac.uk/21510/

Cotton, Matthew and Charnley-Parry, Ioan ORCID: 0000-0003-1847-3036

(2018) Beyond opposition and acceptance: examining public perceptions of the environmental and health impacts of unconventional oil and gas

extraction. Current Opinion in Environmental Science \& Health . ISSN 24685844

It is advisable to refer to the publisher's version if you intend to cite from the work. http://dx.doi.org/10.1016/j.coesh.2018.01.001

For more information about UCLan's research in this area go to http://www.uclan.ac.uk/researchgroups/ and search for <name of research Group>.

For information about Research generally at UCLan please go to http://www.uclan.ac.uk/research/

All outputs in CLoK are protected by Intellectual Property Rights law, including Copyright law. Copyright, IPR and Moral Rights for the works on this site are retained by the individual authors and/or other copyright owners. Terms and conditions for use of this material are defined in the policies page. 


\title{
Beyond opposition and acceptance: examining public perceptions of the environmental and health impacts of unconventional oil and gas extraction.
}

\author{
Matthew Cotton ${ }^{1}$ \\ Ioan Charnley-Parry ${ }^{2}$
}

Authors pre-print version. Final version forthcoming in Current Opinion in Environmental Science and Health.

\begin{abstract}
This review of public perceptions of unconventional oil and gas exploration identifies four main types of study. First, UOG is analysed in terms of specific environmental and public health impacts. Second, by examining socio-economic impacts (namely the development of energy boom-towns). Third, in terms of the relationship between prior knowledge of UOG technology and public attitudes of support or opposition. Fourth, in terms of framing and discursive analysis of UOG by stakeholder groups including the print media. We identify a specific knowledge gap for environmental health professionals: that research is needed into how public and environmental health messages can be best communicated to diverse communities potentially affected by fracking, in order to directly improve public health outcomes.
\end{abstract}

\section{Highlights}

- The public perceptions literature is analysed in the context of primary health impacts (from environmental harm) and secondary impacts from boomtown development

- Four main areas of research of identified - specific impacts, public understanding, perceptions of socio-economic impacts, framing analyses.

- Further research needed into the effects of public health perceptions on other health behaviours, and the most effective communicative strategies to achieve community health outcomes.

\section{Introduction}

The rapid development of unconventional oil and gas (hereafter UOG) resources, from tight sands, shales and coal seams using horizontal drilling and hydraulic fracturing techniques, is a growing international energy policy concern. The potential profitability of UOG, as revealed in the shale boom occurring in the US, has popularised so-called fracking globally. Aside from the USA, countries such as China, Argentina, Algeria, Canada, Mexico, Australia, South Africa, Russia and Brazil (in descending order of resource magnitude) have all embarked upon shale development programmes [1], whilst smaller reserves in Europe (e.g. Denmark, the UK and Poland) have estimated net profitability and political support for extraction activities. Political support for UOG is motivated by energy security of supply, rural economic regeneration and taxation revenue concerns. UOG development is, however, banned in some countries (e.g. Scotland, Ireland and Germany), and within some regional state-level

\footnotetext{
${ }^{1}$ Department of Environment, University of York, York, YO10 5DD. United Kingdom

${ }^{2}$ Energy and Society Research Group, UCLan Energy, University of Central Lancashire, Preston, PR1 2HE. United Kingdom.
} 
administrations (e.g. New York, Maryland in the USA, or Victoria in Australia). Others have moratoria in place (e.g. New South Wales in Australia) in light of documented environmental and health impacts. Government-level action to block UOG development is often motivated by lack of trust in oil and gas industry actions to protect local communities from harm [2], and this, in turn, is influenced by public perceptions of the economic, social, environmental and health implications of the technology at local, national and international scales.

\subsection{Primary environmental impacts}

The health impacts of UOG are well documented. As a fossil fuel, UOG elevates the long-term global environmental health impacts associated with climate change (through fugitive methane emissions, and contributions to the total carbon budget) [3], although gas has a lower carbon footprint to coal, produces lower NOx, SO2, black carbon, $\mathrm{CO}$, mercury and particulates than the shale gas lifecycle at a mass per energy base and so is often framed as a transition fuel for short-term decarbonisation of fossil-fuel based energy systems [4]. Yet despite its environmental performance relative to coal, there remain a number of environmental health impacts from UOG that are both local and immediate. These include exposure to hazardous materials: air pollutants, ground and surface water contamination with hydraulic fracturing fluids [5], naturally occurring radioactive materials (NORM) in waste-water returns [6], risks to communities and workers from seismic events [7], vehicle traffic-associated risks (including collisions [8] and air quality impacts [9]), accidents and malfunctions, and light and noise pollution [10]. Air and water impacts, particularly from exposure to fracking additives, have documented negative health effects including nervous system, respiratory and gastrointestinal health risks, cancer risks [11] and increased incidence of infant mortality [12]. This collective public and environmental health research has identified the key point and non-point source pollutants and their potential metabolic effects. However, as Adgate el. note [13], there are persistent uncertainties about various factors and metrics. These include the frequency and duration of human exposure to chemical contaminants, the heterogeneous pollution monitoring, control and mitigation strategies in place, and a paucity of baseline environmental health data against which to measure community impact. Therefore, there is a need for integrated studies of public health, environmental and socio-economic impact data [14], and both Cooper et al.'s [15**] comprehensive review of UOG sustainability and Meng's [16**] total environment assessment are useful in further defining this knowledge gap.

\subsection{Secondary socio-economic and health impacts}

Aside from directly measurable impacts, there are also associated social impacts that have secondary effects upon community health. The concept of the energy "boomtown" has been subject to sustained sociological inquiry since the 1970s. Boomtowns involve rapid exploitation of a new resource, leading to an influx of new, non-local employees, and new infrastructure and investment models to rural community. Though positive economic benefits are strongly attributed to new extractive developments there are numerous negative impacts. These include aesthetic and amenity value loss, loss of access to the outdoors and wildlife habitats, housing and infrastructural shortages leading to price increases and housing poverty, environmental injustice and heightened crimes rates, in turn leading to elevated incidence of psychosocial stress [17], substance abuse and depression [18, 19]. Sociological research on the boomtown concept has specific attribution to case studies of UOG development [20-23], however, Jacquet's [24**] review notes that social scientific focus upon whether boomtown conditions exist in UOG communities leaves a research gap on repeated, longitudinal, data collection and analysis on social impacts to better understand the long-term effects. Moreover, 
although there is strong evidence on the primary and secondary community health impacts of UOG development (alongside other community resource extraction and energy project cases), until recently, less attention has been given to the subjective interpretations of such energy developments [25], and the impact that public perceptions have upon UOG development decisions and outcomes.

\section{Discussion - public perceptions of unconventional oil and gas}

Within the public health literature, there is an important need to understand not just the biophysical impacts of UOG-related risks, but also the socio-cultural and psychological dimensions of risk perception, and the effect that these have upon resource development. As Werner et al. [26*] note, there is a clear gap in scientific knowledge with regards to public health perceptions and concerns, a need for research comparing public perceptions on health risks with epidemiological risk data, and a need for improved risk communication with affected communities. This is important because public opinion has substantial effects upon policy decisions, even when such opinions run counter to the activities of political organizations and industry elites [27]. For these reasons, we must better understand the differentiated reasoning for support or opposition to UOG, the underlying mechanisms that drive such differentiated support, and the effect that this has upon natural resource extraction and energy policy choice.

When considering specific environmental risks, water withdrawal, contamination and quality have been primary concerns since the start of the shale boom, particularly in the USA [28], with Thomas et al. [29**] noting that water impacts are among the most commonly cited and important environmental risks, with air pollution, damage to the land and landscape, and associated impacts on wildlife as common secondary concerns. However, rather than focus on specific environmental impacts, much work on UOG perceptions examines top-level, framing or discursive construction of shale gas risks (whereby certain aspects are emphasised and others minimised in scientific and political communication and how this influences public opinion and the range of policy choices available). In European studies of shale gas perceptions, social science researchers have commonly employed qualitative and/or documentary methods of discourse analysis, media and stakeholder interviewing. These studies examine issues of how key industry and policy communicators socially construct UOG technology, for example, by comparing it with coal in order to frame it as a clean or transition fuel [30]. Numerous studies have shown that certain industry framings lead to a lack of trust within local communities, and how such lack of trust in policy authority, industry and regulatory messages (and their messengers) undermines local support (sometimes referred to as social license to operate) [2, 31-34]. Recent research using both deliberative methods and survey data has shown how local support is influenced by perceptions of UOG as being beneficial to climate change (or vice versa) [35*], as being based in both place-based (local) experiences as well as national energy and environmental policy contexts [36, 37], and how issues such as media framing at the national level [38], or even the use of 'fracking' terminology (with its lewd connotations), skews public perception [39].

When looking at support and opposition-influencing framing effects, there is considerable variation between and within countries. For example, greater pro-UOG messages are emerging within media and government messages in countries such as Poland [38], at local state levels in regions with higher levels of current or historic oil and gas exploration than those without such experience [40], and between policy-makers (who emphasize economic regeneration) and non-expert citizens (who emphasize environmental justice) [41]. One clearly important framing effect is the way in which UOG is framed as either an "environmental" or an "energy" 
problem. Thomas et al.'s review [29**] concludes that those who more readily cite economic and energy supply impacts are more likely to support fracking, whilst those who more readily cite environmental impacts are more likely to be opposed to UOG development, and that benefits and risks are commonly perceived to be "economic" and "environmental", respectively.

In addition to study of the top-down framing of UOG, empirical research on the 'bottom-up' public understanding/perceptions of UOG and the contexts in which they emerge has been explored in quantitative survey work. There is a high proportion of recent social science work on perceptions in the US that analyses the relationship between demographic characteristics and the factors that influence their relative support or opposition. For example, there is evidence of strong support amongst younger men [42], social conservatives [43, 44], and ranchers and land-owners (which tend to be concerned more about revenue and social impacts than environmental restoration) [45], when compared to other demographic groups. In European public perceptions work there has been greater emphasis upon the role of public knowledge of UOG and its influence upon public support or opposition, as is appropriate to studying this an emergent technology (certainly less established than the US). Cooper et al. find that public awareness of UOG costs and benefits in Europe is comparatively higher than that of the US [15], whilst Stedman et al. [46] find that increased knowledge has differential effects on support in different contexts -in the UK it is associated with increased support, whereas in the US case it had no effect on support. Yet other domestic US studies [40] find that citizens have limited familiarity with fracking processes and their potential impacts, but have increased familiarity and association with environmental impacts, correlating strongly with opposition fracking. This was also found in smaller, non-representative sample data of public perceptions [47]; and mirrored in a Spanish national-level case study, where issues of proximity and prospect of shale gas extraction were strong influencers of public opinion [48]. In contrast, surveys in Texas communities found limited knowledge of fracking processes and impacts, that in turn led to misconceptions related to environmental health risks and possibly increase public risk concerns [49]. Whereas in the UK, the reverse appears true. Whitmarsh et al. [50*] show that prior knowledge is associated with more favourable attitudes, with greater attitude change effects amongst the most ambivalent respondents. Knowledge of fracking as a predictor of support or opposition is important because good policy-making on fracking is commonly framed by Government sources as being based upon comprehensive one-way communication of fracking risks to 'the public', despite evidence to the contrary $[46,51]$. The assumption is that more knowledge will improve public support, invoking the so-called 'deficit model' of science communication (involving top-down, one-way communication to fill an imagined knowledge gap that will improve public support for the technology in question).

\section{Conclusions}

There are a number of key patterns within the UOG perceptions literature shown across four dimensions in figure 1. The focus upon public perceptions of the technology and specific impacts (notably water), the framing of fracking, and the demographic characteristics of opponents and supporters, reveal specific research gaps pertinent to environmental and public health research and practice. The first is that the rapid emergence of the North American UOG industry has meant that US research on public perceptions focused upon sites with high levels of development. We concur with Thomas et al. [29**] that the Marcellus shale formation in Pennsylvania has been heavily researched at the expense of "upstream locations" where UOG is an emergent or imminent phenomenon. Also, more broadly, there is little published research on public perceptions in other non-US UOG-affected countries: China, Argentina, Algeria, 
Brazil, and Russia all have massive unconventional resources, and yet we lack access to published data either due to lack of research or linguistic barriers in publication. Comparing across international cases on issues such as trust, the prioritisation of specific health outcomes, the conditionality of risk acceptance and public understanding of the technology would provide a fruitful new source of data.

Figure 1. Categorisation of existing public perceptions research

\begin{tabular}{|c|c|}
\hline $\begin{array}{l}\text { Perceptions of specific health } \\
\text { and environmental impacts }\end{array}$ & $\begin{array}{l}\text { - Air quality } \\
\text { - Water quality/water stress } \\
\text { - Naturally occurring radioactive materials } \\
\text { - Seismic activity } \\
\text { - Traffic accidents } \\
\text { - Noise and light pollution } \\
\text { - Relevant references }[\mathbf{1 0}, \mathbf{1 1}, \mathbf{1 3}, \mathbf{1 6 , 1 7 , 2 6 , 3 7 , 4 2 , 4 3 , 4 9 ]}\end{array}$ \\
\hline $\begin{array}{l}\text { Public understanding of } \\
\text { unconventional oil and gas } \\
\text { technology }\end{array}$ & 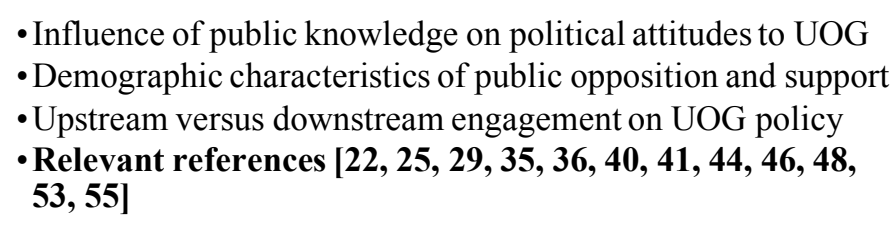 \\
\hline $\begin{array}{l}\text { Perceptions of socio- } \\
\text { economic benefits, risks and } \\
\text { governance arrangements }\end{array}$ & 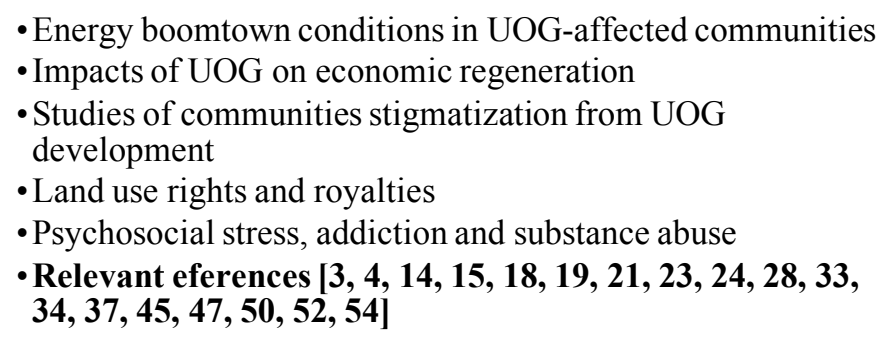 \\
\hline $\begin{array}{l}\text { Discourse, linguistic and } \\
\text { framing analysis }\end{array}$ & $\begin{array}{l}\text { - Social construction of UOG technology in print and social } \\
\text { media } \\
\text { - Dominant storylines/social representations of UOG by } \\
\text { stakeholders } \\
\text { - Influence of public perceptions on energy/resource } \\
\text { management policy } \\
\text { - Relevant references }[\mathbf{2}, \mathbf{2 0 , 3 0 , 3 1 , 3 8 , 3 9 , 5 1 ]}\end{array}$ \\
\hline
\end{tabular}

In the US/EU context, given the wealth of public perceptions data, as Cotton [52], Israel et al. [53] and Whitton et al. [54] suggest, more attention needs to be paid to the conditions under which communities are engaged with, and have policy-making control over future UOG through mechanisms of public participation, and how evidence on public perceptions and the conditions of public acceptance can be applied in practical land use planning for UOG. In European research, there is greater emphasis upon the "upstream" i.e. the conditionality of risk perception and how it fits with environmental governance regimes. However, in both US/EU literatures there is a strong emphasis upon studying the conditions of either acceptance or rejection of the technology - i.e. the motivation for support or opposition. Yet, UOG is now so widespread in certain regions (e.g. Pennsylvania, Texas Colorado, or the Darling Downs in Australia) that understanding opposition and support factors is no longer the most pressing social scientific concern, and the relationship between shale gas perceptions and either other value concerns (e.g. how opposition is strongly correlated to concerns about sustainability, 
whereas support correlates strongly with the concept of resilience [55*]), or how perceptions of shale gas relate to broader energy system transformation and low-carbon transitions at national and international scales [56] is of increasing importance.

From an environmental health perspective, there are two important things that researcher need to consider. Firstly, we need better quality evidence to enhance our understanding of how the presence of UOG development influences the behaviours and social practices of local residents. This is not just a question of assessing whether or not boomtown conditions have emerged, but rather to understand how the technology influences changing patterns of travel, recreation, and employment over time. Understanding how these environmental health risks change patterns of behaviour in other domains of social life, through ethnographic and longitudinal research, would provide a strong indication of effects of unconventional oil and gas development upon the social resilience affected communities. Secondly, for those communities that already have UOG in their locality, we need to better understand the types of practical advice the environmental health professionals can give to those concerned about environmental health risks in their area. This means not only researching and providing good quality environmental health data, but also working with communities to find out what their information needs are, what types of messages would be effective in improving public health outcomes, understanding which messengers would be trusted to provide such information, and what the long-term effects such communication would have upon health outcomes. 


\section{References}

1. U.S. Energy Information Administration. World Shale Resource Assessments. 2015 30/07/2017]; Available from: https://www.eia.gov/analysis/studies/worldshalegas/.

2. Bomberg, E., Shale We Drill? Discourse Dynamics in UK Fracking Debates. Journal of Environmental Policy and Planning, 2017. 19(1): p. 72-88.

3. Few, S., et al., The impact of shale gas on the cost and feasibility of meeting climate targets - A global energy system model analysis and an exploration of uncertainties. Energies, 2017. 10(2): p. 158.

4. Jenner, S. and A.J. Lamadrid, Shale gas vs. coal: Policy implications from environmental impact comparisons of shale gas, conventional gas, and coal on air, water, and land in the United States. Energy Policy, 2013. 53(0): p. 442-453.

5. Michalski, R. and A. Ficek, Environmental pollution by chemical substances used in the shale gas extraction - a review. Desalination and Water Treatment, 2016. 57(3): p. 1336-1343.

6. Brown, V.J., Radionuclides in fracking wastewater: managing a toxic blend. Environmental Health Perspectives, 2014. 122(2): p. A50.

7. Ellsworth, W.L., Injection-induced earthquakes. Science, 2013. 341(6142): p. 142-149.

8. Graham, J., et al., Increased traffic accident rates associated with shale gas drilling in Pennsy/vania. Accident Analysis \& Prevention, 2015. 74: p. 203-209.

9. Rich, A., J.P. Grover, and M.L. Sattler, An exploratory study of air emissions associated with shale gas development and production in the Barnett Shale. Journal of the Air \& Waste Management Association, 2014. 64(1): p. 61-72.

10. Souther, S., et al., Biotic impacts of energy development from shale: research priorities and knowledge gaps. Frontiers in Ecology and the Environment, 2014. 12(6): p. 330-338.

11. Kovats, S., et al., The health implications of fracking. The Lancet, 2014. 383(9919): p. 757.

12. Busby, C. and J.J. Mangano, There's a World Going on Underground-Infant Mortality and Fracking in Pennsylvania. Journal of Environmental Protection, 2017. 8(4): p. 381-393.

13. Adgate, J.L., B.D. Goldstein, and L.M. McKenzie, Potential Public Health Hazards, Exposures and Health Effects from Unconventional Natural Gas Development. Environmental Science \& Technology, 2014. 48(15): p. 8307-8320.

14. Small, M.J., et al., Risks and Risk Governance in Unconventional Shale Gas Development. Environmental Science \& Technology, 2014. 48(15): p. 8289-8297.

15. Cooper, J., L. Stamford, and A. Azapagic, Shale Gas: A Review of the Economic, Environmental, and Social Sustainability. Energy Technology, 2016. 4(7): p. 772-792.

16. Meng, Q., The impacts of fracking on the environment: A total environmental study paradigm. Science of The Total Environment, 2017. 580: p. 953-957.

17. Ferrar, K.J., et al., Assessment and longitudinal analysis of health impacts and stressors perceived to result from unconventional shale gas development in the Marcellus Shale region. International Journal of Occupational and Environmental Health, 2013. 19(2): p. 104-112.

18. Jacobsen, G.D. and D.P. Parker, The economic aftermath of resource booms: evidence from boomtowns in the American West. The Economic Journal, 2014. 126(593): p. 1092-1128. 
19. Perry, S.L., Development, land use, and collective trauma: the Marcellus Shale gas boom in rural Pennsylvania. Culture, Agriculture, Food and Environment, 2012. 34(1): p. 81-92.

20. Mercer, A., K. de Rijke, and W. Dressler, Silence in the midst of the boom: coal seam gas, neoliberalizing discourse, and the future of regional Australia. . Journal of Political Ecology, 2014. 21: p. 279-302.

21. Schafft, K.A., et al., Local Impacts of Unconventional Gas Development within Pennsylvania's Marcellus Shale Region: Gauging Boomtown Development through the Perspectives of Educational Administrators. Society \& Natural Resources, 2014. 27(4): p. 389-404.

22. Wynveen, B.J., A thematic analysis of local respondents perceptions of Barnett Shale energy development. Journal of Rural Social Sciences, 2011. 26(1): p. 8-31.

23. Stedman, R.C., et al., Environmental Reviews and Case Studies: Marcellus Shale Gas Development and New Boomtown Research: Views of New York and Pennsylvania Residents. Environmental Practice, 2012. 14(4): p. 382-393.

24. Jacquet, J.B., Review of risks to communities from shale energy development. Environmental Science \& Technology, 2014. 48(15): p. 8321-8333.

25. Theodori, L., Paradoxical Perceptions of Problems Associated with Unconventional Natural Gas Development. Southern Rural Sociology, 2009. 24(5): p. 97-117.

26. Werner, A.K., et al., Environmental health impacts of unconventional natural gas development: a review of the current strength of evidence. Science of the Total Environment, 2015. 505: p. 1127-1141.

27. Burstein, P., The impact of public opinion on public policy: A review and an agenda. Political Research Quartlery, 2003. 56(1): p. 29-40.

28. Kreuze, A., C. Schelly, and E. Norman, To frack or not to frack: perceptions of the risks and opportunities of high-volume hydraulic fracturing in the United States. Energy Research \& Social Science, 2016. 20: p. 45-54.

29. Thomas, M., et al., Public perceptions of hydraulic fracturing for shale gas and oil in the United States and Canada. Wiley Interdisciplinary Reviews: Climate Change, 2017. 8(3).

30. Cotton, M., I. Rattle, and J. Van Alstine, Shale gas policy in the United Kingdom: an argumentative discourse analysis. Energy Policy, 2014. 73: p. 427-438.

31. Cotton, M., Stakeholder perspectives on shale gas fracking: a Q-method study of environmental discourses. Environment and Planning A, 2015. 47(9): p. 1944-1962.

32. Goldstein, B.D., O. Renn, and A.S. Jovanovic, Public Health, Risk Perception, and Risk Communication: Unconventional Shale Gas in the United States and the European Union, in Environmental and Health Issues in Unconventional Oil and Gas Development, D. Kaden and T.L. Rose, Editors. 2016, Elsevier: Amsterdam. p. 107127.

33. Mrozowska, S., et al., Trust in the source of received information as a factor related to public perception of shale gas drilling. Current Issues in Personality Psychology, 2016. 4(4): p. 240-252.

34. Bradshaw, M. and C. Waite, Learning from Lancashire: Exploring the contours of the shale gas conflict in England. Global Environmental Change, 2017. 47: p. 28-36.

35. Partridge, T., et al., Seeing futures now: Emergent US and UK views on shale development, climate change and energy systems. Global Environmental Change, 2017. 42: p. 1-12. 
36. Thomas, M., et al., Deliberating the perceived risks, benefits, and societal implications of shale gas and oil extraction by hydraulic fracturing in the US and UK. Nature Energy, 2017. 2: p. 17054.

37. Evensen, D. and R. Stedman, Beliefs about impacts matter little for attitudes on shale gas development. Energy Policy, 2017. 109: p. 10-21.

38. Jaspal, R., B. Nerlich, and S. Lemańcyzk, Fracking in the Polish press: Geopolitics and national identity. Energy Policy, 2014. 74: p. 253-261.

39. Evensen, D., et al., What's the 'fracking' problem? One word can't say it all. The Extractive Industries and Society, 2014. 1(2): p. 130-136.

40. Boudet, H., et al., "Fracking" controversy and communication: Using national survey data to understand public perceptions of hydraulic fracturing. Energy Policy, 2014. 65: p. 57-67.

41. Crowe, J., et al., Differences in public perceptions and leaders' perceptions on hydraulic fracturing and shale development. Sociological Perspectives, 2015. 58(3): p. 441-463.

42. Olawoyin, R., et al., Environmental health risk perception of hydraulic fracturing in the US. Cogent Environmental Science, 2016. 2(1): p. 1209994.

43. Brasier, K.J., et al., Residents' perceptions of community and environmental impacts from development of natural gas in the Marcellus shale: a comparison of Pennsylvania and New York cases. Journal of Rural Social Sciences, 2011. 26(1): p. 32-61.

44. Choma, B.L., Y. Hanoch, and S. Currie, Attitudes toward hydraulic fracturing: The opposing forces of political conservatism and basic knowledge about fracking. Global Environmental Change, 2016. 38: p. 108-117.

45. McGranahan, D.A., F.N. Fernando, and M.L.E. Kirkwood, Reflections on a boom: Perceptions of energy development impacts in the Bakken oil patch inform environmental science \&amp; policy priorities. Science of The Total Environment, 2017. 599-600: p. 1993-2018.

46. Stedman, R.C., et al., Comparing the relationship between knowledge and support for hydraulic fracturing between residents of the United States and the United Kingdom. Energy Research \& Social Science, 2016. 20: p. 142-148.

47. Schafft, K.A., Y. Borlu, and L. Glenna, The relationship between Marcellus Shale gas development in Pennsy/vania and local perceptions of risk and opportunity. Rural Sociology, 2013. 78(2): p. 143-166.

48. Costa, D., et al., Understanding public perception of hydraulic fracturing: a case study in Spain. Journal of Environmental Management, 2017. 204(1): p. 551-562.

49. Whitworth, K.W., et al., Exploring perceptions of fracking and environmental health in a 3-county population in South Texas. Journal of Epidemiological Research, 2017. 3(1): p. 61.

50. Whitmarsh, L., et al., UK public perceptions of shale gas hydraulic fracturing: The role of audience, message and contextual factors on risk perceptions and policy support. Applied Energy, 2015. 160: p. 419-430.

51. Williams, L., et al., Framing 'fracking': Exploring public perceptions of hydraulic fracturing in the United Kingdom. Public Understanding of Science, 2017. 26(1): p. 89-104.

52. Cotton, M., Fair fracking? Ethics and environmental justice in United Kingdom shale gas policy and planning. Local Environment, 2017. 22(2): p. 185-202. 
53. Israel, A.L., et al., Eliciting public concerns about an emerging energy technology: the case of unconventional shale gas development in the United States. Energy Research \& Social Science, 2015. 8: p. 139-150.

54. Whitton, J., et al., Shale Gas Governance in the United Kingdom and the United States: Opportunities for Public Participation and the Implications for Social Justice. Energy Research and Social Science, 2017. 26: p. 11-22.

55. Evensen, D., R.C. Stedman, and B. Brown-Steiner, Resilient but not sustainable? Public perceptions of shale gas development via hydraulic fracturing. Ecology and Society, 2017. 22(1).

56. Bridge, G., et al., Geographies of energy transition: Space, place and the low-carbon economy. Energy Policy, 2013. 53(0): p. 331-340. 